\title{
Experimental Analysis of Prosthetic Knee Joint
}

\author{
C.Shashishekar ${ }^{1}$, Prashanta ${ }^{2}$, S.J. Sanjay ${ }^{3}$ \\ ${ }^{1}$ Associate Professor, Mechanical Engineering, Siddaganga Institute of Technology Tumkur, Karnataka. \\ ${ }^{2}$ PG - Mechanical Engineering, Basaveshwar Engineering College Bagalkot, Karnataka. \\ ${ }^{3}$ Assistant Professor, Mechanical Engineering, Basaveshwar Engineering College Bagalkot, Karnataka.
}

\begin{abstract}
The aim of this research was to study the distribution of contact stresses in prosthetic knee joint made up of polyethylene material. Commercially available software ANSYS 18.1 used in numerical experimental. The effect of the sagittal radius, flexion angle and external load on stresses in the knee joint were investigated in numerical experiments. The compare results for experimental method and FEA method.

So Overall, this investigation gives a rule to creation of prosthetic knee joint at sensible expense with better arrangement of sagittal radius and flexion angle to withstand the loads under different circumstances.
\end{abstract}

Keywords: Knee joint, tibia, femur, polariscope, sagittal radius, flexion angle.

\section{INTRODUCTION}

The knee joint is complex structure in the human body which undergoes critical loading simultaneously while performing different physical activities such as walking, running, in rotational motion, sitting, static positions etc. what we used to do in our day to day life. Major parts in a knee joint are femur, tibia, patella and meniscus. It has two articulation components one is in between the tibia and femur and another between the femur and patella [1]. Articular disc present in the knee joint is called meniscus. It is made with two components such as medial and lateral meniscus.

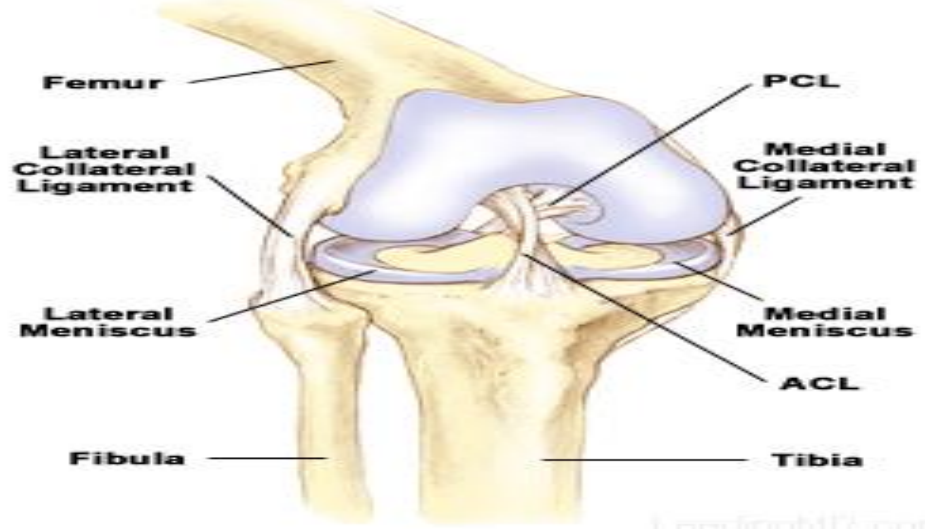

Fig 1. Knee joint

\section{METHODOLOGY}

\subsection{Preparation of photoelastic model}

The mould cavity of knee joint component is made by using acrylic sheets having a thickness of plate and cavity plate $5 \mathrm{~mm}$ each. The lesser quantity of hardener HY-951, is adding to CY-230 resin is accepted in preparations. The hardener and resin are added in 1:5 ratio respectively. Hence, based on the size of the component these two are mixed. As the reaction is exothermic more quantity of hardener is used for larger casting. As both materials are in liquid state, they can be easily measured by jars. The lesser measured units of hardener slowly added to measured resin in another jar. The mixture must be fifty minutes. Then mixture of hardener and resin poured in mould cavity of knee joint component. Solidification of room temperature about $56 \mathrm{hrs}$. 


\section{International Advanced Research Journal in Science, Engineering and Technology}

Vol. 8, Issue 9, September 2021

DOI: 10.17148/IARJSET.2021.8913

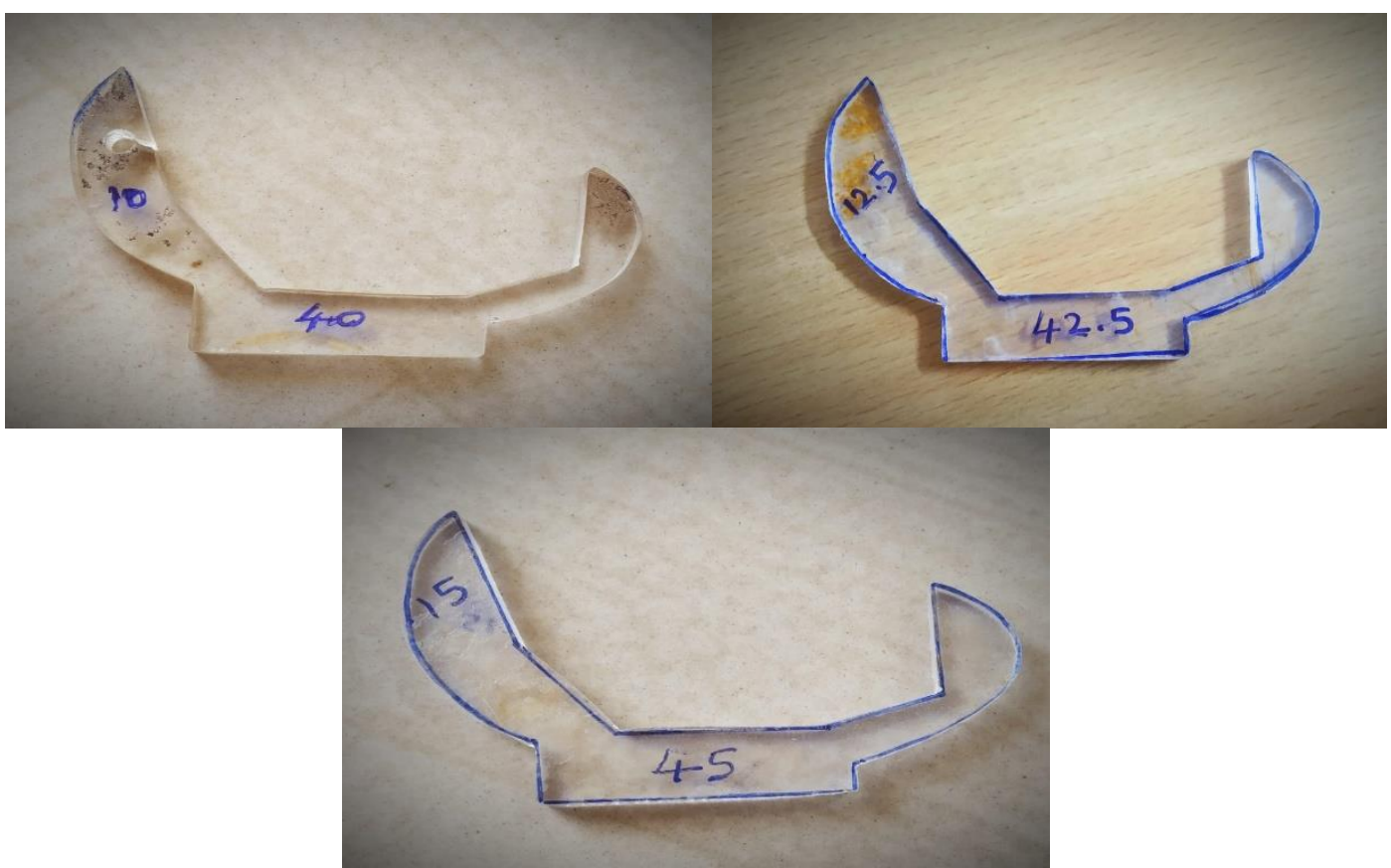

Fig 2. Photoelastic model

\subsection{Photoelasticity}

Photoelasticity is an experimental method by using captivated light is gone through a focused on straightforward model, interference patterns or fringes are formed. These patterns provide immediate qualitative information about the general distribution of stress, positions of stress concentrations and of areas of low stress. On the basis of these results, designs may be modified to reduce or disperse concentrations of stress or to remove excess material from areas of low stress, there by achieving reductions in weight and material costs. As photoelastic analysis may be carried out at the design stage, stress conditions are considered before production. where it gives a picture of stress distribution around discontinuities in materials. Photoelastic fringe patterns are shown in below. Usually Two-Dimensions stress systems are analyzed this method. Its working principle given by Maxwell's stress optic law.

The equation is

Where,

$$
\sigma=\frac{\mathrm{NF} \sigma}{\mathrm{h}}
$$

\section{$\sigma$ - Stress}

$\mathrm{N}$ - Number of fringes

Fo- Fringe value

$\mathrm{h}$ - Thickness

\subsection{Experimental set up}

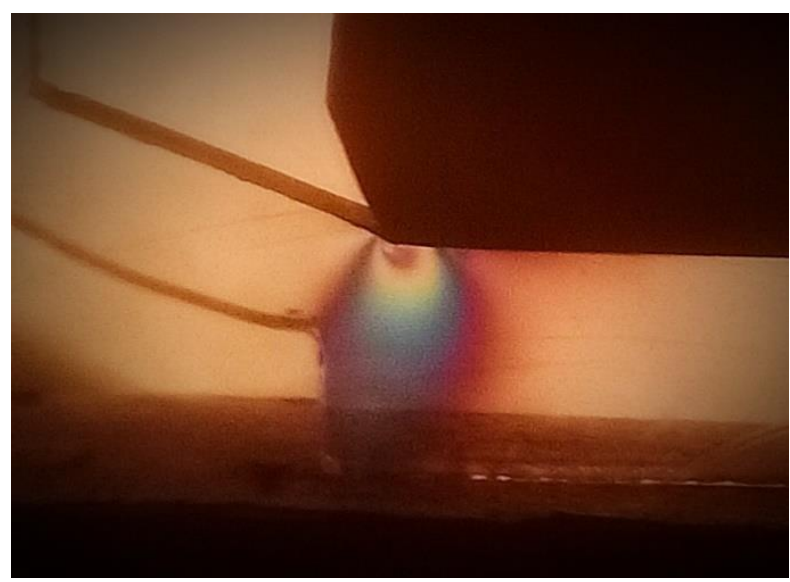

Fig 3. Fringe Order

The experimental setup of photo elasticity model with polariscope consist of a monochromatic light source, polarizer, analyzer and load frame is show in figure. The polariscope is an optical instrument that can produce a polarized light and 


\title{
International Advanced Research Journal in Science, Engineering and Technology
}

\author{
Vol. 8, Issue 9, September 2021
}

\section{DOI: 10.17148/IARJSET.2021.8913}

can measure the resulting phase difference when the polarized light passes through a stressed photoelastic model. It can resolve a light vector into transmitted and absorbed orthogonal components. The axis parallel with the transmitted component is called as axis of polarization. Hence the two axes are perpendicular to each other, no light will be transmitted through the analyzer when the transparent model is stress free, and dark field will result.

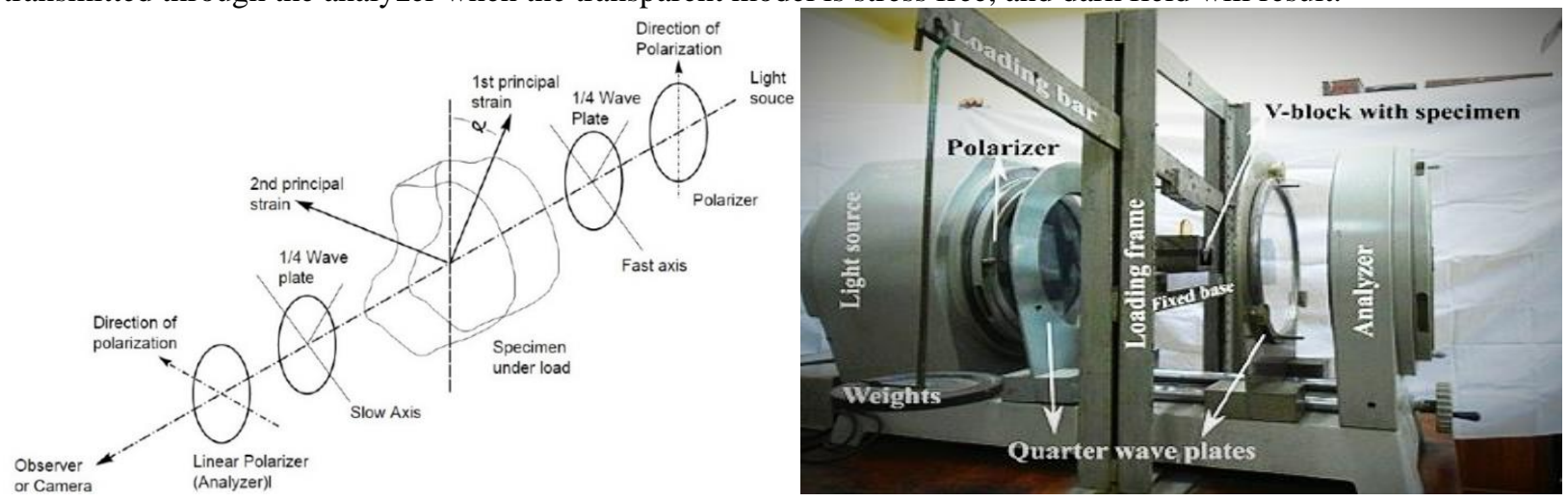

Fig 4. Schematic of the experimental set up

Fig 5. Experimental set-up of polariscope

\subsection{Various optical arrangement}

Conventional optical arrangement to set dark or bright field.

\begin{tabular}{|l|l|l|l|}
\hline \multicolumn{1}{|c|}{ Set up } & Polarizer and Analyzer & Quarter wave plates & Background \\
\hline Plane Polariscope & $\begin{array}{l}\text { Crossed } \\
\text { Crossed }\end{array}$ & $\begin{array}{l}\text { None } \\
\text { Crossed }\end{array}$ & $\begin{array}{l}\text { Dark } \\
\text { Dark }\end{array}$ \\
\hline Circular Polariscope & $\begin{array}{l}\text { Crossed } \\
\text { Parallel } \\
\text { Crossed }\end{array}$ & $\begin{array}{l}\text { Crossed } \\
\text { Parallel } \\
\text { Parallel }\end{array}$ & $\begin{array}{l}\text { Dark } \\
\text { Dark } \\
\text { Bright }\end{array}$ \\
\hline
\end{tabular}

Polarizer: -A filter for converting randomly polarized light into plane polarized light and which is located immediately in front of the light source.

Analyzer: -A filter at the viewing end of the polariscope. The polarizer and analyzer are optically identical, and thus named to distinguish their respective function.

Quarter wave plates: -An optical element for inducing $1 / 4$ of a wavelength of relative retardation between two spatially perpendicular component light rays. The transmission polarizer contains two-quarter wave plate -one in conjunction with polarizer, and one in conjunction with the analyzer.

Plane polarized light: -Light characterized by having the transverse vibrations limited to a single plane for a ray, or to parallel planes for a beam.

Circularly polarized light: -Light in which the plane of polarized rotates continuously with propagation of the light ray. Circularly polarized is produce when the vibration of two component rays of equal amplitude are perpendicular to each other on space and $1 / 4$ of a wavelength out phase.

Fringe: -Generically, colored or black lines, bands, or areas forming the photoelastic pattern, and representing loci of constant different in principal stresses. Specifically, in the case of isochromatic fringes, the tint-of passage in white light, or the centers of the dark bands in monochromatic light.

Isochromatic: -A fringe (single-colored in white light, essentially black in monochromatic light) representing a locus of constant difference in principal stresses (stress-stain) as the locus of constant maximum stress.

Isoclinic: -A black line representing a locus of constant direction of principal stresses, or in other words, constant inclination of the principal axes with respect to an arbitrary reference axis.

Monochromatic light: -Light of only one wavelength.

\subsection{Calculation of Photoelastic stress}

From stress-optic law, this relationship is expressed as,

$\left(\sigma_{1}-\sigma_{2}\right)=\frac{\mathrm{NF} \sigma}{\mathrm{h}} \quad \mathrm{N} / \mathrm{mm}^{2}$

Where,

$\sigma_{1}$ and $\sigma_{2}=$ Algebraically Maximum and Minimum principal stresses, in N/mm ${ }^{2}$

$\mathrm{F}_{\sigma}=$ Material fringe value expressed in $\mathrm{N} / \mathrm{mm}$.

$\mathrm{N}=$ Fringe order. 


\section{International Advanced Research Journal in Science, Engineering and Technology}

Vol. 8, Issue 9, September 2021

DOI: 10.17148/IARJSET.2021.8913

$\mathrm{h}=$ Thickness of the model, in $\mathrm{mm}$.

Consider a circular model (knee joint model is assumed to be half circle shape), then

$\mathrm{F}_{\sigma=\frac{8 \mathrm{P}}{\pi \mathrm{NN}}} \cos \alpha$

$\mathrm{P}=$ Load applied in $\mathrm{N}$.

$\mathrm{D}=$ Diameter of the model.

$\mathrm{N}=$ Number of the fringes.

$\alpha=$ Flexion angle.

For photoelastic model of sagittal radius $40 \mathrm{~mm}$ and flexion angle $10^{0}$

$\mathrm{P}=150 \mathrm{~N}, \mathrm{~h}=5 \mathrm{~mm}, \mathrm{D}=80 \mathrm{~mm}, \mathrm{~N}=2, \alpha=10^{0}$

Therefore,

$\mathrm{F}_{\sigma=} \frac{8 \mathrm{P}}{\pi \mathrm{DN}} \cos \alpha$

$\mathrm{F}_{\sigma=} \frac{8 * 150 * 10}{\pi * 80 * 2} \cos 10^{0}$

$\mathrm{F}_{\sigma=} 23.51$

Now stress calculated as,

$\sigma=\frac{\mathrm{NF}_{\sigma}}{\mathrm{h}}=\frac{2 * 23.51}{5}=9.40 \mathrm{~N} / \mathrm{mm}^{2}$

\subsection{Finite Element Analysis of Knee Joint}

The finite element method is a widely used method for numerically solving differential equations and mathematical modelling. Typical problem areas of interest include the traditional fields of heat transfer, fluid flow structural analysis, mass transport. The finite element method is a generally numerical method and solving partial differential equations in two or three space variables. To solve a problem, the FEM subdivides a large system into smaller simpler parts that are called finite element. The finite element analysis of knee joint, the IGES or STP file with femur and tibia is imported in ANSYS 18.1.

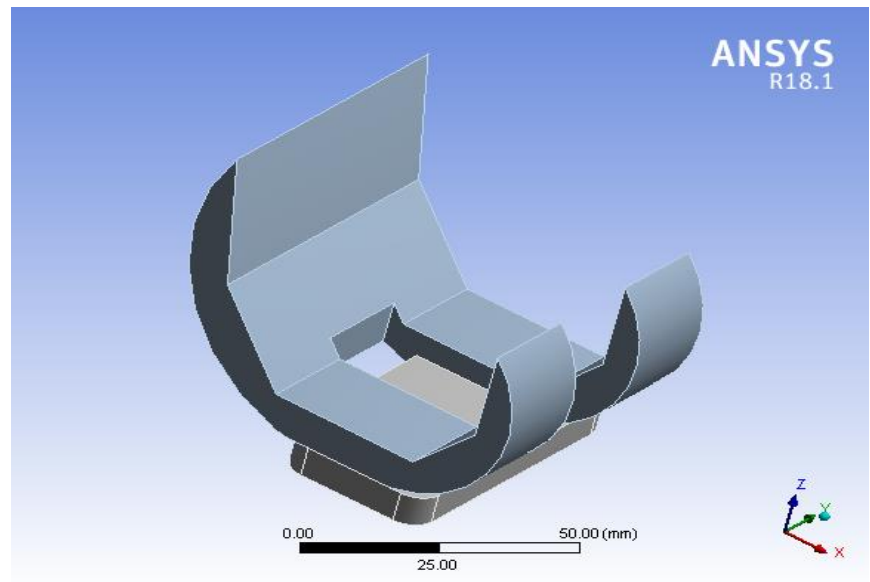

Fig. 6. Design of knee joint

\section{RESULTS AND DISCUSSION}

The experimental stress analysis has been carried out in polariscope machine and find out stresses for various load conditions, and also find out the von-mises stress and deformation of knee joint by finite element analysis method. The results listed below table 5.1 and 5.2. 
DOI: $10.17148 /$ IARJSET.2021.8913

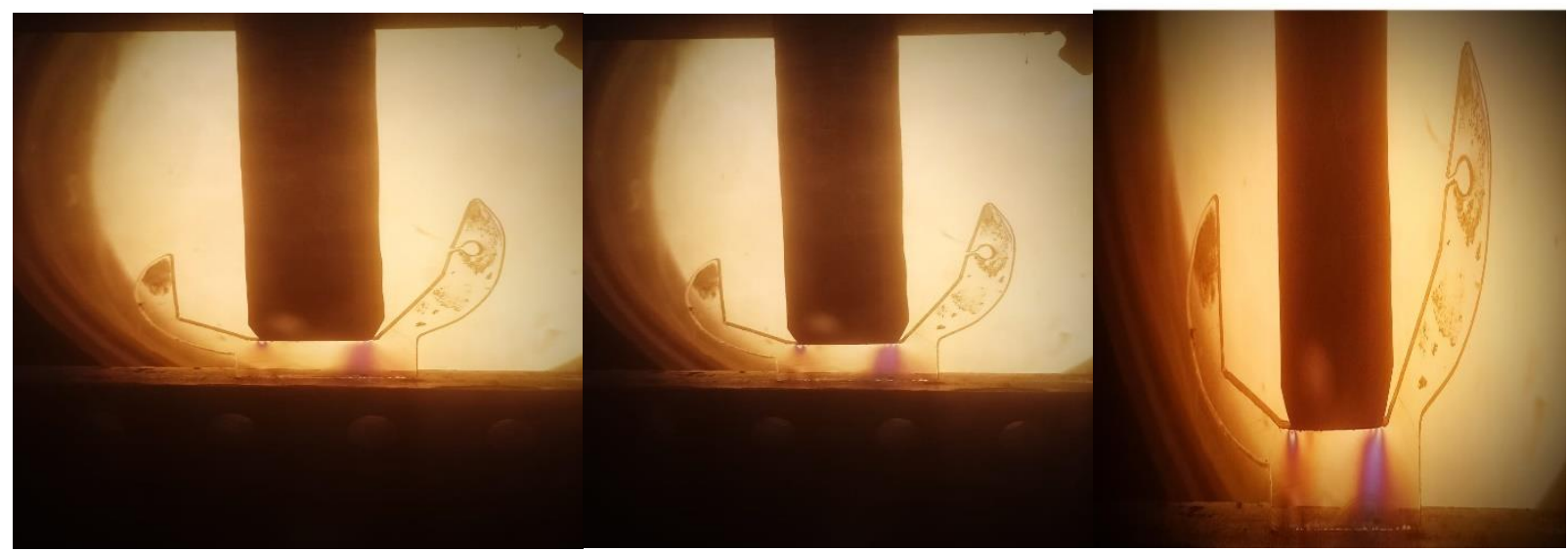

Fig.7. Radius 40,42.5,45 and flexion angle 10,12.5,15 respectively

\subsection{Mesh model}

The finite element model was generated by meshing the solid model 50 brick element. The results of the analysis depend on the quality of meshing. Meshing starts with assigning a seed on the parts. This determines the mesh density at particular region of the part. The tibial model was constrained in all degrees of freedom (DOF) at its lower surface. The femoral model was rigidly fixed. A compressive load was applied to the femoral component at the bearing points at different flexion angles.

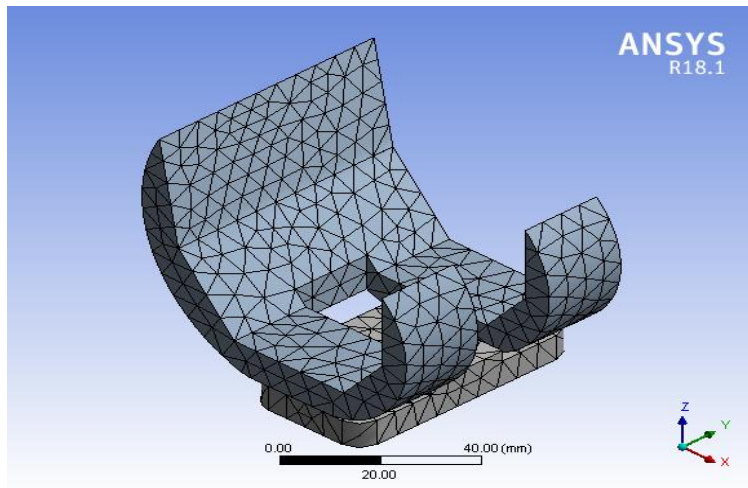

Fig. 8. Mesh model
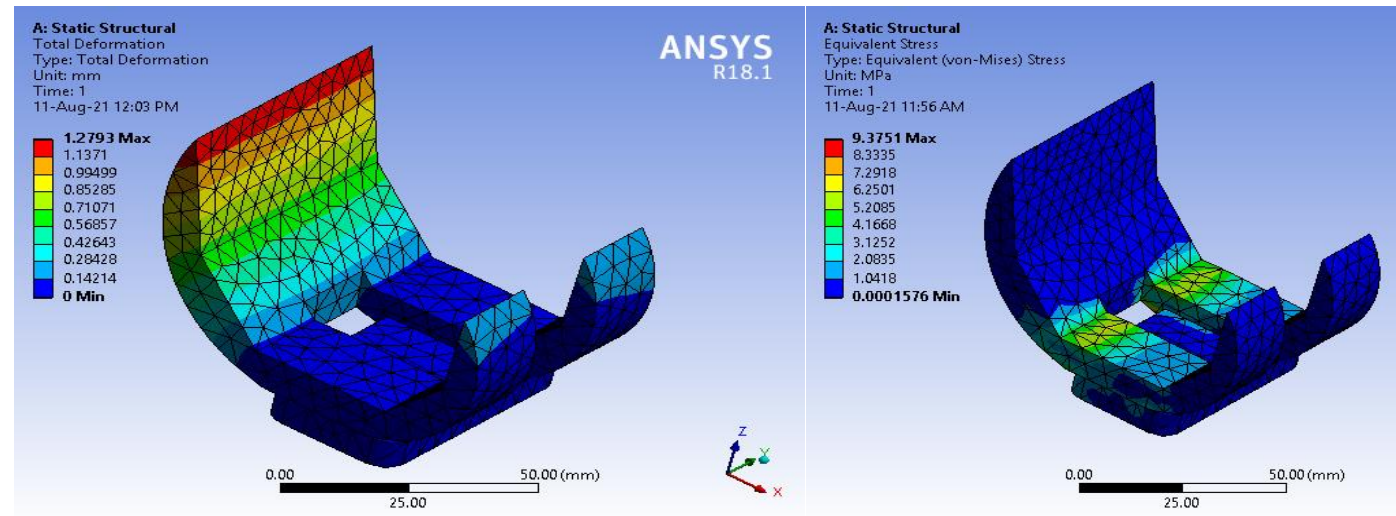

Fig.9. Deformation and von mises stress at sagittal radius 40 and flexion angle $10^{\circ}$ 
DOI: 10.17148/IARJSET.2021.8913

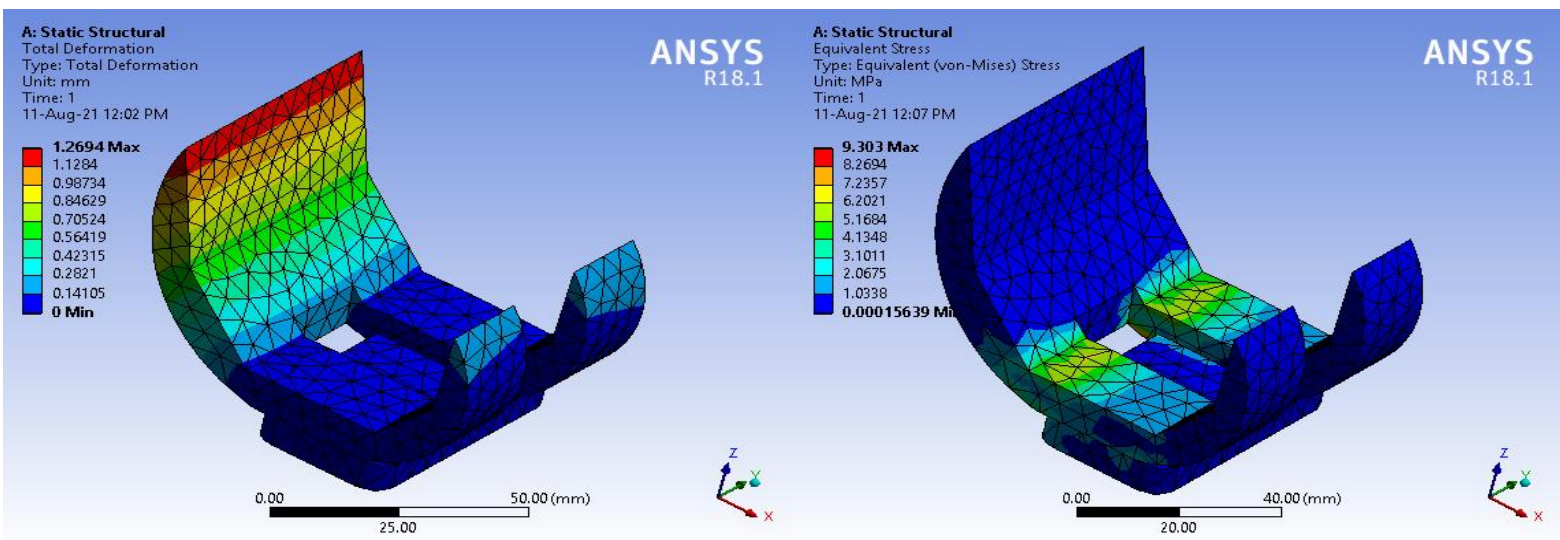

Fig.10. Deformation and von mises stress at sagittal radius 40 and flexion angle $12.5^{0}$

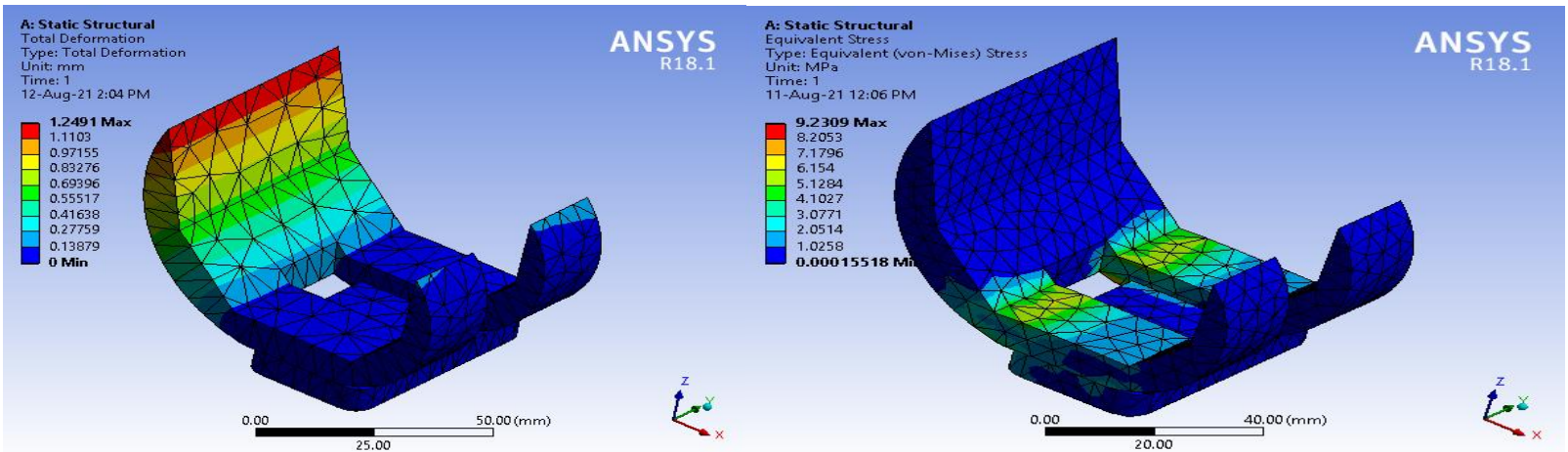

Fig.11. Deformation and von mises stress at sagittal radius 40 and flexion angle $15^{0}$

The graph it is observed the experimental method and finite element analysis using different sagittal radius and flexion angle as shown in below graph.

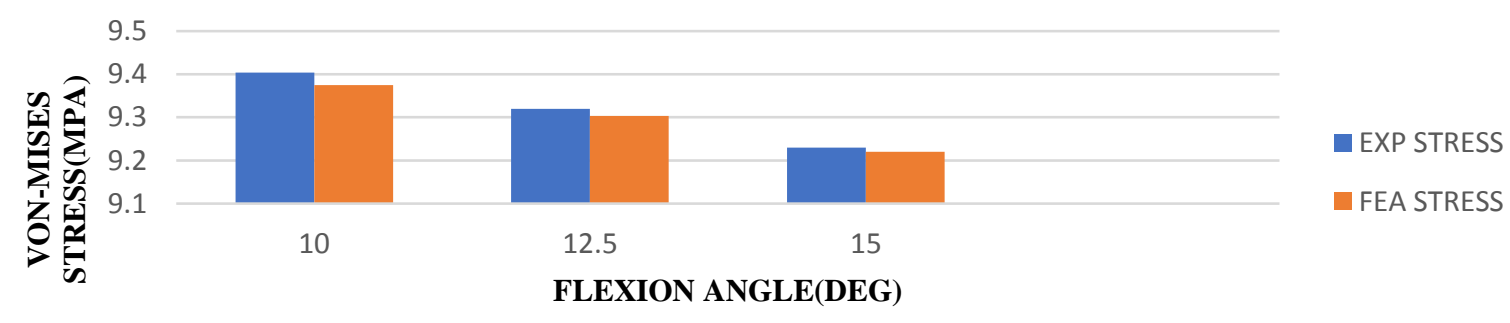

\section{Total Deformation}

Fig.12. Experimental vs FEA method using 40mm radius

We can observe that in case of total deformation, knee joint made up of polyethene is found to have least deformation $1.102(150 \mathrm{~N})$, the sagittal radius and flexion angle at X-axis and deformation is $\mathrm{Y}$ - axis. 


\section{International Advanced Research Journal in Science, Engineering and Technology}

Vol. 8, Issue 9, September 2021

DOI: 10.17148/IARJSET.2021.8913

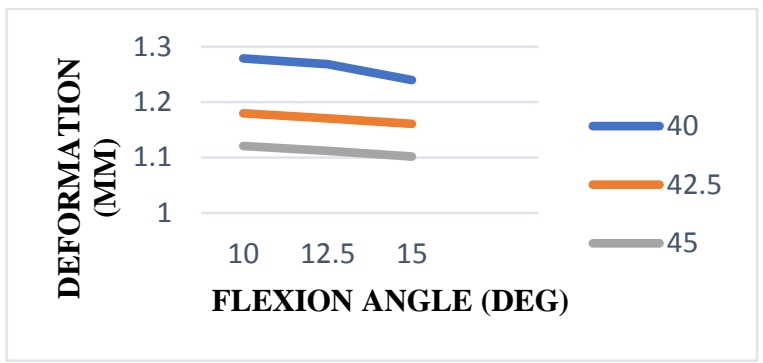

Fig.13. Deformation

\section{CONCLUSION}

In deviation it is observed that the percentage of deviation for Experimental to FEA results is smaller than +5 hence they are acceptable.

- In this study the design approach for a tibia and femur component using solid edge software has been developed.

- In this study we had done von-mises stress, deformation and safety factor for prosthetic knee joint with different load condition.

\section{REFERENCES}

1. Zaffagnini, S, "A Standardized Technique in Performing Pivot-Shift Test on the Knee Joint Provided More Consistent Acceleration Curve Shape, Allowing to Highlight Side-to-Side Differences". The Journal of Arthroscopic and Related Surgery, 2013. 29(10): p. e175-e175.

2. Haque, M.A., T. Kurokawa, and J.P. Gong, "Super tough double network hydrogels and their application as biomaterials". 2012. 53(9): p. 18051822.

3. Metzger.,"Patient specific knee alignment guide associated method". 2012, Google Patents

4.Padhi, A.K., "Development of a Limb prosthesis by reverse mechanotransduction". 2013.

5. Baran, G.R., M.F. Kiani, and S.P. Samuel, "Biomaterials Applications in Medicine and Case Studies, in Healthcare and Biomedical Technology in the 21st Century". 2014, Springer. p. 249-265.

6. Carr, A.J., "Knee replacement. The Lancet", 2012. 379(9823): p. 1331-1340.

7.Ali M. Alsamhan, “ Rationale analysis of human artificial knee replacements”.2016.

8. M. venkata Pavan Kumar, I.Bhanulatha, "Design and structural analysis of knee implants using different materials"

9. Nirsandh G; Preetha S; Sabeer yaccob. "Arthroplasty Advancement: Remodification Design of Total Hip Replacement". International Research Journal on Advanced Science Hub, 2, 6, 2020, 105-108. doi: 10.47392/irjash.2020.45

10. Sathyamoorthy V; R.Santhosh Kumar; Sreedhar S; Sridhar M; Surendhar S. "Design and Analysis of Adoptable Multipurpose Tillage Equipment". International Research Journal on Advanced Science Hub, 2, 7, 2020, 123-125. doi: 10.47392/irjash.2020.75 